\title{
Switching from petro-plastics to microbial polyhydroxyalkanoates (PHA): the biotechnological escape route of choice out of the plastic predicament?
}

\author{
Martin Koller
}

\begin{abstract}
The benefit of biodegradable "green plastics" over established synthetic plastics from petro-chemistry, namely their complete degradation and safe disposal, makes them attractive for use in various fields, including agriculture, food packaging, and the biomedical and pharmaceutical sector. In this context, microbial polyhydroxyalkanoates (PHA) are auspicious biodegradable plastic-like polyesters that are considered to exert less environmental burden if compared to polymers derived from fossil resources.

The question of environmental and economic superiority of bio-plastics has inspired innumerable scientists during the last decades. As a matter of fact, bio-plastics like PHA have inherent economic drawbacks compared to plastics from fossil resources; they typically have higher raw material costs, and the processes are of lower productivity and are often still in the infancy of their technical development. This explains that it is no trivial task to get down the advantage of fossil-based competitors on the plastic market. Therefore, the market success of biopolymers like PHA requires R\&D progress at all stages of the production chain in order to compensate for this disadvantage, especially as long as fossil resources are still available at an ecologically unjustifiable price as it does today.

Ecological performance is, although a logical argument for biopolymers in general, not sufficient to make industry and the society switch from established plastics to bio-alternatives. On the one hand, the review highlights that there's indeed an urgent necessity to switch to such alternatives; on the other hand, it demonstrates the individual stages of the production chain, which need to be addressed to make PHA competitive in economic, environmental, ethical, and performance-related terms. In addition, it is demonstrated how new, smart PHA-based materials can be designed, which meet the customer's expectations when applied, e.g., in the biomedical or food packaging sector.
\end{abstract}

Keywords: Bioeconomy, Bioengineering, Biopolyesters, Biopolymers, Downstream processing, Industrial waste, Next Generation Industrial Biotechnology (NGIB), Polyhydroxyalkanoates (PHA), Raw Materials; Sustainability

University of Graz, Institute of Chemistry, NAWI Graz, Austria

ARENA (Association for Resource Efficient and Sustainable Technologies), Graz, Austria

Corresponding author: M. Koller E-mail: martin.koller@uni-graz.at

DOI: 10.2478/ebtj-2019-0004

\section{Introduction: The current plastic scenario}

Humanity has gone through several significant epochs during its evolution. Important examples in the past were were the stone age and the diverse metal ages; currently, we not only live in the silicon age, moreover, we are also in the middle of the "plastic age". Each of these epochs was or is, respectively, marked by quantum leaps in the use and evolution of novel materials that have been permanently integrated in response to the ever-growing demands of an intellectually and organizationally exponentially advancing society. Based on the multifarious beneficial properties of plastics, they are among the most widely produced and applied materials in our today's world; regarding their low density, convenient processability, stability and flexibility, plastics have undisputed countless advantages over materials used in previous centuries, such as metals or minerals, but they also carry a lot of environmental and health risks (1). One could say that today, plastics emerged to an indispensable evil (2). As a matter of fact, the growing amounts of petrol-based plastics used for various purposes of our daily life are among the fundamental ecological grievances of 
our modern time. In this context, we are currently threatened by headwords dominating the media like "growing dumps of plastic garbage", "marine ecosystems contaminated by plastics", "microplastic", and, very recently, political initiatives to "ban all-day plastic commodities" such as wide spread plastic shopping bags, cotton swabs with plastic rods, plastic cutlery, or plastic beakers (3).

Indeed, 330 megatons (Mt) of petrochemical plastics are currently produced globally per year. Producing them depletes limited available fossil raw materials; moreover, after being used, these petrochemical "full-carbon-backbone plastics" must be supplied to appropriate disposal strategies due to their high recalcitrance towards biodegradation. Until now (2018), an estimated quantity of $150 \mathrm{Mt}$ of plastic waste has already entered the oceans; as a shocking estimate, this marine plastic waste is supposed to cause the death of about 100,000 marine mammals and about one million birds annually (4). Recently, the medially disseminated death of a sperm whale, which carried an incredible quantity of around eighty plastic bags in its digestive tract, which made it impossible for this marine giant to absorb organic nutrients, had upset the general community (5). In November 2018, another perished whale was found at the Indonesian coast; in the stomach of this animal, a total of $6 \mathrm{~kg}$ of plastics was found, inter alia 115 plastic cups, 25 plastic bags and more than 1000 other plastic parts (6). Especially microplastics have also direct effects on security of human nutrition; such plastics particles of a size of less than $5 \mathrm{~mm}$ easily pass through the whole food supply chain until they finally reach it's end, namely the human body (7-9). In this context, food production often resorts to equipment made of plastic parts, which causes microplastic formation by abrasion, while food storage in plastic containers and bottles is another direct source of food contamination by microplastics (10). Only by now, the scientific community starts to mechanistically understand the harmful effects of microplastics on the human organism, and to estimate these effects qualitatively and quantitatively. Just the other day (autumn 2018), a total of nine different petrochemical plastics, predominantly polypropylene (PP) and polyterephtalate (PET) with particle sizes between 50 and $500 \mu \mathrm{m}$ were for the first time identified by an Austrian research team in the human intestinal system; it is suspected that these microparticles can potentially be forwarded from the intestine to the blood and the lymphatic system and to various organs (11). Apart from plastics themselves, other products associated to polymer production and processing cause harmful effects to the human metabolism, such as crude oil-based $o$-phthalate or diverse other plasticizers; also these additive need replacement by biological alternatives, as manifested by very recent studies (12).

Regarding the problem of landfilling for final disposal of plastic, it should be noted that in Europe not even a third of plastic waste undergoes recycling; the rest ends up in landfills, pollutes terrestrial and aquatic environments or the forests, or is simply combusted in waste incineration plants (3). In the context of recycling, which is often extolled as a universal remedy to treat plastic waste, it should be mentioned that this strategy rather delays than avoids its final disposal in landfills or incineration. On the other hand, considerable parts of landfilled plastic discards arrive via detours, such as wind or river systems, into the oceans, where they cause the above described fatal effects on living beings (11). In the EU alone, this plastic migration from landfills to the sea applies to annually about $500,000 t$ of plastic rejects. Needless to say, this leads to a significant burden on the entire global ecosystem and human health. Also from a resource-political point of view, the exuberant production and use of plastic is more than shortsighted, unsustainable, and actually inadmissible. This does not just mean that plastic manufacturing leads to the exploitation of fossil resources; in addition, one has to keep in mind that most of the plastic items used today are for single use only. This situation acts as an as anplifier of the ecological misery insofar as many plastic objects can, on the one hand, easily be produced, and, on the other hand, they are very cheap, which hardly promotes any change in the mental attitude of broad sections of the population towards not using them (4).

In order to change this situation, rational and ecological pricing of conventional plastic materials is required, which not only takes into account the benefits of such polymers, but also accounts for the environmental burden caused by their high ecological footprint. As a result, plastic would no longer be disposed of en masse. In addition, fair pricing, wherever possible and reasonable, would encourage the development and production of bio-inspired, sustainable alternatives.

\section{Biological alternatives to established plastics}

To an increasing extent, biopolymers with plastic-like properties are considered potential alternatives to replace well-established petrochemical plastics on the market; among these bio-alternatives, thermoplastic starch, poly(lactic acid), or, as the topic of this review, microbial polyhydroxyalkanoates (PHA), are in the spotlight of current R\&D endeavors (13). Especially $\mathrm{PHA}$, a family of microbial biopolyoxoesters produced as intracellular storage compounds by numerous bacteria and a range of extremophilic haloarchaea, are nowadays in the focus of microbiologists, polymer scientists, process engineers, and, more recently, scientists involved in synthetic biology. What makes PHA that fascinating are the tunable material features, which enables their implementation in numerous sectors of the plastics market; here, they have the potential to displace diverse currently dominating petrol-based plastomers and technomers $(14,15)$. Most of all, PHA are the only family of so called "green plastics" sensu stricto, because they are biobased (biosynthesis starting from renewable resources), biosynthesized (intracellular products of the secondary metabolism of prokaryotic microbes), biodegradable, compostable, and fermentable to products like water, $\mathrm{CO}_{2}$, or $\mathrm{CH}_{4}$; moreover, they are biocompatible, which makes them attractive as materials of choice for biomedical applications. Production of these biological plastics does not deplete fossil resources because of being derived from renewable resources. Their entire life span is embedded into the closed carbon cycle of nature, which implies that their 


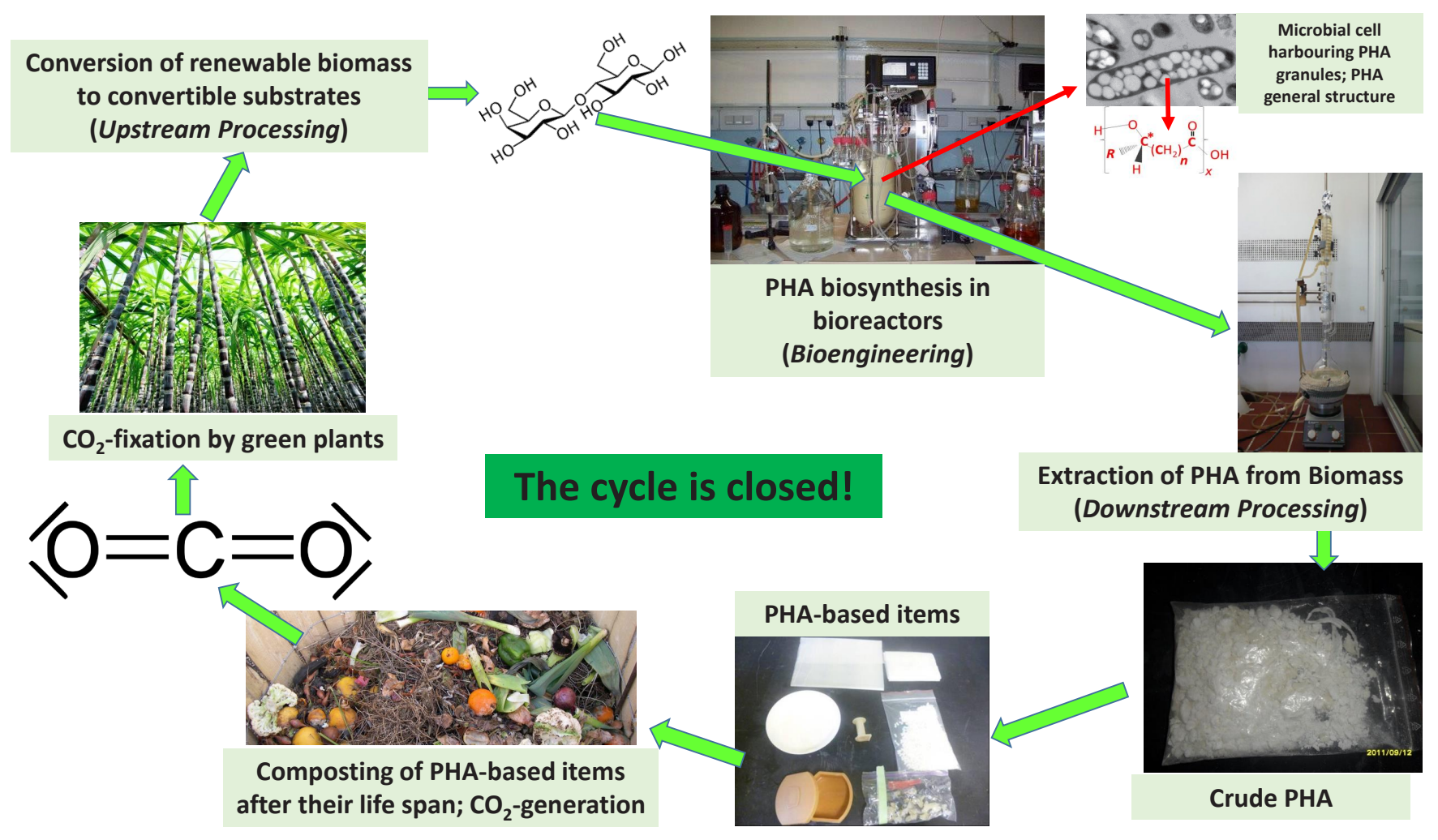

Figure 1. Closed carbon cycle during production, life span, and degradation of PHA biopolyesters.

degradation, in contrast to degradation of petro-based plastics, does not cause an increase of the atmospheric $\mathrm{CO}_{2}$ level; hence, it does not amplify or accelerate climate change (Fig. 1) (16). Feedstocks typically used to manufacture PHA and other "green plastics" are renewable resources like sugars, high-molecular carbohydrates or fats and oils, which are natural products and substrates of the carbon cycle of living beings. It should be visualized that, in contrast to fossil resources used to produce established plastics, these renewable feedstocks were not captured within Earth's interior since eons. After the use of biopolymers, they undergo biodegradation and composting by the metabolism of living organisms, which generates biomass and $\mathrm{CO}_{2}$; $\mathrm{CO}_{2}$, in turn, gets fixed again by the photosynthetic performance of green plants to rebuild the renewable feedstocks originally used for biopolymer synthesis, which closes the cycle of anabolism and catabolism of biopolymer feedstocks. This differs drastically from the life-cycle processes of petrochemical plastics, the thermal degradation of which results in a misbalance of $\mathrm{CO}_{2}$ through combustion; excess carbon that has been removed from the natural carbon cycle over millions of years is suddenly released into the atmosphere as surplus $\mathrm{CO}_{2}$ (Fig. 2). It would take millions of years to recover fossil fuels by means of photosynthetic fixation and fossilization of the resulting biomass (16).

In fact, this sounds promising, so why don't we just switch to these biopolymers? Indeed, we have to consider ethical, economic and sustainability aspects especially when selecting the adequate raw material for biopolymer production, such as for biosynthesis of PHA. It is exhaustively reported that using nu- tritionally important carbohydrates like sugars or edible oils for PHA production results in high product formation rates, with numerous fermentation protocols being available for diverse production strain-substrate combinations; this goes as well for laboratory scale experiments as well as for (semi)industrial PHA production processes. However, applying such edible substrates for bioplastic production on a larger scale cannot be accepted based on the high number of people suffering from starvation on this planet; using such edible resources to feed PHA-producing microbes fuels the current "plate-versus-plastics" conflict, as does using converting food resources for biofuel production, which provokes the "plate-versus-tank" controversy (14). This makes clear that simply replacing established plastics by biobased alternatives cannot be considered the one and only panacea for the plastic problem, when the reflection of the entire process chain and biopolymer life cycle is not warranted (17). A sustainable biopolymer production process has to take aspects of cost-efficiency, environmental protection, optimized engineering, and ethics into consideration (14). As a more and more acknowledged exit strategy out of this predicament, one could link food industry with biopolymer industry in a synergistic way. Companies involved in food and feed production and processing produce huge quantities of carbon-rich waste streams, which could be used at zero costs as feedstocks by biopolymer producing companies (18). To underline the feasibility and importance of this still new paradigm, one should keep in mind that an estimated annual quantity of about $10^{12} \mathrm{~kg}$ of food is not consumed by humans, but simply rejected (19). Substituting purified carbon feedstocks by such waste streams 


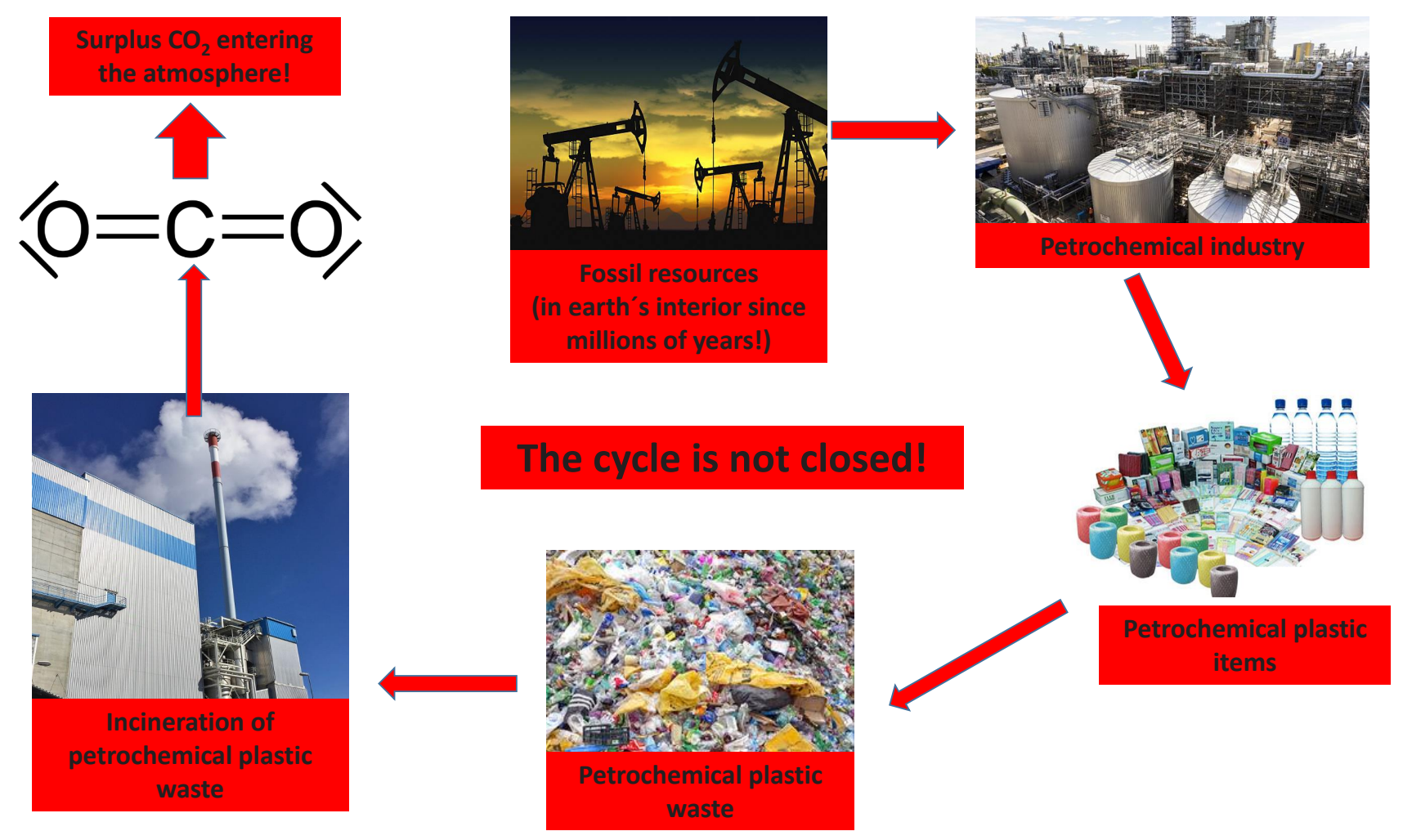

Figure 2. Carbon cycle during production, life span, and degradation of petrochemical plastics: the cycle is not closed.

of the food-industrial sector on the one hand safes about $50 \%$ of the entire costs of the biopolymer production chain, and, on the other hands, provides (agro)industry a tool to upgrade their disposal products in a value-generating manner (20). Examples of (agro)industrial waste used as PHA-feedstock during the last years, albeit not yet beyond the laboratory scale, encompass molasses from sugar industry $(21,22)$, hydrolysates of lignocellulose materials (23) like bagasse (24), wheat straw (25), rice straw $(26)$, or wood $(27,28)$, sugars obtained by hydrolysis of green grass (29) or saccharified ryegrass (30), empty oil palm fruit bunches (31), cellulose-digested corn stover (32), steamed soybean wastewater (33), waste glycerol from biodiesel production (34-37), saturated biodiesel fractions of animal origin $(38,39)$, waste office paper hydrolysate $(40)$, or spent sulfite liquor obtained by chemical pulping during the paper production process (41). From gastronomy, hydrolyzed spent coffee grounds (42) or waste cooking oil (43) are available as PHA feedstocks at ample quantity. Only recently, even petrochemical plastic waste (polyethylene) was successfully converted to PHA (44). On an almost pilot scale of some 100 $\mathrm{L}$, lactose-rich surplus whey from dairy industry was used for production of PHA copolyesters by the haloarchael production strain Haloferax mediterranei (45).

In contrast to the use of pure, defined feedstocks, it is pivotal to understand the composition of such complex carbon sources, and the impact of eventually present inhibiting compounds on growth and biopolymer production kinetics of a selected microbial production strain. Therefore, it is important to develop proper upstream processing methods to convert a waste stream into a biotechnological feedstock. In this context, it is often needed to hydrolyze di-, oligo-, or polymeric compounds into smaller substrates, which are easily convertible by the microbial production strain (46). Moreover, such complex mixtures of hydrolysis products frequently contain inhibitors, which require removal for detoxification $(28,47)$. Beside the use of food and agricultural waste as biotechnological substrates to cultivate microbial production strains, it is an emerging R\&D trend to apply a range of surplus materials from agriculture and food production as filler materials to generate new biocomposites. This encompasses, e.g., lignocellulosics like bagasse and straw, wood dust, or cellulose (nano)fibers. Properties of such new biopolymer composite materials can be fine-tuned by triggering the ratio of biopolymer (PHA, PLA, thermoplastic starch, etc.), the filler material, and eventual additional plasticizers like glycerol or special plant oils; this way, one can achieve unprecedented, customized material properties and high performance in terms of, e.g., gas permeability, crystallinity, compression behavior, elongation-at-break, and others. Hence, smart bioplastic composite materials to be used in defined fields of the plastic market can be developed, finetuned to a special purpose, such as food packaging, automotive parts, and many more (48-50).

Now, it's already more than nine decades ago, since Maurice Lemoigne described for the first time the microscopic observation of PHA granules as light-refractive inclusions in Bacillus megaterium cells (reviewed by 51). Typically, PHA synthesis in microbes is boosted when the cells are exposed to conditions of limited availability of a growth-essential nutrient, in most 
cases nitrogen or phosphate, in parallel to sufficient supply with exogenous carbon source (substrate). As their principal biological role as carbon- and energy reserve compounds, presence of PHA enables microbial cells to better endure periods of carbon starvation. In its role as "electron and NADH sink", PHA regenerates reducing equivalents under conditions when central metabolic pathways, mainly the tricarboxylic acid cycle (TCC), are shut down, as it is the case when culturing cells under nitrogen limited conditions. Here, PHA biosynthesis is a "pseudofermentative" strategy applied by microbes to keep their metabolism running (52). More recently, the scientific community revealed the significant protective role of PHA against a number of stress factors, which are harmful or even lethal for PHA-free microbial cells (53). In this context, it was demonstrated that presence of PHA exerts a protective effect against the impact of elevated temperature (54), attenuates the destructive impact of excessive UV-irradiation by scattering light (55), helps to repair damage caused by repeated freezing-and-thawing cycles (56) or sudden osmotic imbalances (57), and elevates the burdens caused by chemical oxidants in general (58), and by sudden generation of reactive oxygen species (ROS) in particular (59). Regarding elevated salt concentrations (hyperosmotic conditions), presence of PHA granules in living microbes turned out to support the cells to better survive the harmful effects of osmotic up-shock; this also clarifies why PHA granules are found in so many haloarchaeal species isolated up to date from extremely saline ecological niches (57).

\section{Microbiology and genetic engineering to support PHA biosynthesis and production}

PHA bioproduction can be carried out either using established wild type strains, new mesophilic $(60,61)$ or extremophilic $(62,63)$ microbial isolates, or, to an increasing extend, by using genetically modified strains. Such genetic modifications ("genome editing") of PHA-accumulating microbes have originally been carried out to understand the principal biochemical, enzymatic, genetic, and metabolic features of PHA biosynthesis and intracellular degradation of these biopolyesters. Only since the last couple of years, we witness a switch from genetic manipulation of PHA producers for academic interest towards the design of new powerful cellular platforms for high-throughput biosynthesis of tailor-made PHA, preferably from inexpensive feedstocks. These activities are embedded in the topical field of "Next Generation Industrial Biotechnology" (NGIB), which describes the use of robust, genetically tailored production strains in large-scale industrial bioprocesses, often operated under restricted sterility precautions (64).

In the meanwhile, genetic manipulation was already tested to improve all the stages of the PHA production process (65), from the optimization of substrate uptake and utilization (prime example: insertion of $\beta$-galactosidase genes in PHA producers not able to utilize lactose as substrate) (66)), the optimization of oxygen availability to enhance biomass growth by expression of bacterial hemoglobin (67), boosted PHA productivity under oxygen-limited conditions (68), CRISPR/Cas9 genome editing to enhance the pathways leading to poly(3-hydroxybutyrate-co-3-hydroxyvalerate) (PHBHV) biosynthesis (69)), the pre-determination of the monomeric PHA composition by knocking out specific pathways (prime example: designing $\beta$-oxidation weakened mutants to generate PHA homopolyesters consisting of medium-chain-length building blocks (70), or to generate PHA with pending aromatic side chains under controlled conditions (71)). Moreover, synthetic biology approaches, hence, the construction of artificial metabolic pathways in production strains, enable the production of high-quality PHA copolyesters from simple, unrelated carbon sources, as demonstrated by the poly(3-hydroxybutyrate-co-3-hydroxyhexanoate) (PHBHHx) production from glucose as sole carbon source by genetically engineered Pseudomonas stutzeri (72), or by poly(4-hydroxybutyrate) ( $\mathrm{P} 4 \mathrm{HB})$ hyperproduction from glucose by recombinant Escherichia coli (73). Even for downstream processing (prime example: insertion of genes encoding nuclease, which, after cell breakdown, facilitates separation of released PHA granules from the liquid phase), genome editing was reported as a tool for process improvement (74).

From the economic point of view, the development of engineered microbes able to convert inexpensive substrates (waste streams) into PHA is of particular significance (75). As a matter of fact, many natural microorganisms can synthesize PHAs with wide-ranging monomeric composition, which impacts the material properties of PHA. However, incorporation of diverse building blocks in growing PHA chains in most cases requires co-feeding bacteria with structurally related precursor substrates, which are frequently expensive, water insoluble, and inhibiting already at low concentration levels (76). This makes the production of PHA copolyesters of fine-tuned composition problematic especially on industrial scale. Therefore, a current R\&D direction follows the exploitation of such microbial wild type or genetically engineered strains able to convert inexpensive renewable carbon sources towards desired PHA building blocks without the need to supplement established precursors; a prime example in this context is the above reported production of $\mathrm{P} 4 \mathrm{HB}$ from glucose (73). In addition to economic considerations related to the substrate(s) used, particular attention must be dedicated to the microbial aspects of the process. Most of all, substrate-to-product (PHA) conversion yields need to be improved, either by optimizing the cultivation conditions (e.g., triggered oxygen supply to avoid excess $\mathrm{CO}_{2}$ and byproduct formation), or, to an increasing extent, by genetic engineering in order to divert the metabolic carbon flux predominately towards PHA biosynthesis instead of towards production of side-products like organic acids or $\mathrm{CO}_{2}$.

\section{Bioengineering/Fermentation for advanced PHA production}

PHA production under controlled conditions, especially on a larger scale, is typically carried out in bioreactors $(77,78)$; such bioreactors (previously also known as "fermenters") can be operated in different modes, such as batch (substrate feed only at the beginning, product harvest only at the end of the 
process), fed-batch (repeated substrate supply according to substrate analysis, harvest only at the end), and continuous (permanent supply of substrates and products harvest) setups. In this context, PHA biosynthesis has to be understood as a multiphase process, because product (PHA) accumulation as a intracellular secondary metabolite is typically not coupled to the preceding phase of microbial growth (formation of active biomass). Therefore, both feeding strategy and bioreactor operation mode need to be carefully adapted to the selected production strain, substrate, and kinetics of growth and product formation (79). Traditional PHA production setups operated in batch (80), repeated batch ("fill-and-empty" or "drain-and-fill" cultivation) (81), fed-batch (82), or cyclic fed-batch mode (83) often show unsatisfactory control of PHA composition, and are often characterized by modest volumetric productivity $(77,78)$.

The above discussed use of (agro)industrial waste streams as feed streams, which often contain the carbon sources in a considerably diluted form, makes the operation in batch- or fed-batch mode impracticable; each re-feed drastically increases the volume of the bioreactor content (78). In such cases, fedbatch feeding processes coupled to cell recycling were recently developed, where a membrane module is directly coupled with the bioreactor due retain active biomass, but to discard substrate-poor fermentation broth; promising volumetric PHA productivities are reported for such setups, which also avoids an accumulation of inhibiting compounds in the fermentation broth (84).

A detailed understanding of the kinetics of microbial growth and PHA biosynthesis is needed for advanced continuous cultivation processes, which can be carried out in single-, two-, and multi-stage bioreactor arrangements. Optimizing such continuous processes implies matching the kinetics of microbial growth and PHA accumulation with the operation mode (dilution rate, etc.). Such continuous processes not only allow for high volumetric productivity, but also for a better control of the monomeric composition of the products. Moreover, continuous cultivations allow using substrates toxic already at low concentration, such as precursors of special PHA building blocks. While one-stage continuous processes are rather the method of choice for production of compounds of the primary metabolism, but not for secondary products synthesized by multistage processes, as it is the case for PHA, it is beneficial to produce catalytically active biomass in a first continuous stage at high cell densities; in a second stage, this biomass accumulates PHA under nutritionally challenged conditions (e.g., limitation if nitrogen source) at high productivity. In general, such continuous processes offer the possibility to feed the carbon source exactly at the rate as it is consumed by the cells, which causes an almost zero concentration of substrate in spent fermentation broth, thus saving substrate expenses $(85,86)$. Moreover, multistage continuous processes ("bioreactor cascades"), which, with increasing number of individual reactors connected in series, approach the characteristics of tubular plug flow reactors, allow even higher volumetric productivity; the highest volumetric PHA productivity in continuous processes ever of was reported for a 5-stage continuous bioreactor cascade (87). Moreover, such cascades allow for fine-tuning the cultivation conditions in each individual process stage (bioreactor). This offers the advantage of triggering the substrate feed in each stage, which makes it possible to generate blocky structured PHA of pre-defined composition and properties (87-89). In addition, it is possible to study the morphology of cells and PHA granule formation under different defined conditions; the latter is of importance for the final downstream processing, where it is beneficial to have large PHA granules in cells instead of small inclusions, which are more complicated to separate after cell disintegration $(90,91)$.

Gaseous substrates, especially those not or hardly water soluble, require different bioengineering approaches than easily water-soluble heterotrophic substrates. In this context, we currently observe the development of an increasing number of $\mathrm{CO}_{2}$-based PHA production processes, which use cyanobacteria (formerly "blue-green algae") as photoautotrophic cell factories (92-94). Such light-dependent processes resort to discontinuously or continuously operated photobioreactors similar to those used for farming eukaryotic microalgae. In an optimized scenario, the needed substrate $\mathrm{CO}_{2}$ stems from industrial effluent gas; this strategy combines $\mathrm{CO}_{2}$-mitigation with formation of valued bioproducts. To enhance cyanobacterial cultivation, the photobioreactor arrangement needs to be optimized in terms of illumination regime, geometric characteristics, mixing behavior, and gassing/degassing performance. Only recently, a comprehensive review summarized the types of photobioreactors already tested for cultivation of cyanobacteria; it was shown that the optimal photobioreactor design strongly depends on the nutritional and illumination requirements of the individual organisms (95). Recent pilot scale results suggest that tubular photobioreactors might be best suitable for PHA production by cyanobacteria like Synechocytis sp. (96). Apart from cyanobacteria, several hydrogen-oxidizing species such as Idonella sp. are also reported to produce PHA from $\mathrm{CO}_{2}(97,98)$.

In parallel to the gaseous substrate $\mathrm{CO}_{2}$, there are also other C1-compounds available as substrates for PHA production (99). In this context, methane (main product of natural gas and biogas plants) (100), methanol (101), and CO-rich syngas are other emerging substrate options for bioplastic production. In the case of methane, a major greenhouse gas, methanotrophic production strains like Methylocystis sp. were reported to produce PHA at yields exceeding $0.5 \mathrm{~g}$ PHA per $\mathrm{g} \mathrm{CH}_{4}$, which is superior to the theoretical value of heterotrophic $\mathrm{PHA}$ production from sugars, which amounts to $0.48 \mathrm{~g} / \mathrm{g}$ (reviewed by 102). Syngas, obtained by gasification of organic waste, can be converted towards PHA by anaerobic photosynthetic bacteria like Rhodospirillum rubrum (103); also here, tools of genetic engineering were already implemented for process improvement, such as the insertion of genes encoding for mcl-PHA biosynthesis to produce rubber-like PHA from syngas as sole carbon source (104). Of course, the industrial-scale production of PHA from methane or syngas needs bioreactor systems with opti- 
mized gas transfer, such as bubble columns or advanced airlift bioreactors. In the case of methane, a recent review describes the use of loop bioreactors for PHA production based on natural gas; here, it is shown how simulation software tools (computational fluid dynamics and mathematical modelling) help to better understand such biochemical processes. Gas holdup, liquid velocity vectors, shear stress and gas transfer coefficients of the bioreactor need to be studied in order to understand the correlations between the process parameters and product formation, which strongly facilitates the process development and upscaling (105). In the case of syngas, Karmann and colleagues addressed the fact that working with this substrate poses safety risks; therefore, the authors presented a syngas fermentation platform with advanced safety installations and process analytical technology (PAT). Besides measuring devices to control gas supply and consumption, this platform contained an in-line flow cytometer to determine the biomass concentration and intracellular PHA fraction. The platform was used in fedbatch and continuous syngas-based PHA production processes with $R$. rubrum (106).

\section{Advanced downstream processing for sustainable and efficient PHA recovery from biomass}

After biosynthesis, the development of sustainable and inexpensive technologies to recover intracellular PHA from microbial biomass is the final crucial step in the entire PHA production chain. Several comprehensive reviews summarize reported methods for PHA recovery; in principle, such methods resort to the use of practicable PHA-solvents to extract PHA from the cells, the chemical or enzymatic digestion of the microbial biomass accommodating PHA granules, or the mechanical disintegration of the non-PHA cell mass (107-109). Importantly, well-established methods for PHA extraction, which result in best recovery yields and highest product purity, resort to toxic halogenated solvents, predominately chloroform, which should not take part in a sustainable production chain. Therefore, alternative methods for PHA production are currently in status of development, which resort to fundamentally different approaches:

Marudkla and colleagues reported an optimized chloroform-free PHA recovery approach using sodium dodecyl sulfate (SDS) and sodium hypochlorite $(\mathrm{NaOCl})$; optimized by an experimental Taguchi-design, the authors described the optimal conditions for the maximum PHA recovery (78.7\%) when using $0.5 \% \mathrm{w} / \mathrm{v}$ SDS combined with $6 \% \mathrm{v} / \mathrm{v} \mathrm{NaOCl}$. Apart from this chemical method, a new enzymatic approach for digestion of non-PHA biomass was developed by Kachrimanidiou et al., who produced crude enzyme by solid state fermentation of the fungus Aspergillus oryzae. This enzyme cocktail was used to lyse C. necator cells to recover PHA. Temperature and $\mathrm{pH}$-value were optimized for highest $C$. necator lysis, which amounted to about $90 \%$; PHA recovery yield and purity amounted to $98 \%$ and $97 \%$, respectively (110).

Among new solvent-based methods for PHA extraction, the use of the green solvent dimethyl carbonate (DMC) is de- scribed. DMC is completely biodegradable and less harmful to humans and the environment than the established "gold-standard" solvent chloroform. This process can be applied to extract PHA from dry biomass, or even directly to concentrated bacterial fermentation slurries; it results in expediently high polymer recovery rates of more than $85 \%$ and outstanding product purity of more than $95 \%$. In both cases (dry biomass or slurry), the extraction does not cause any degradation of the polymer's molecular mass. Another technique developed in the same study applies fatty acid carboxylates; these surfactants disrupt cell membranes, which sets PHA granules free at excellent polymer recovery rates of more than $99 \%$ and high purity exceeding $90 \%$. Among these surfactants, ammonium laurate can be efficaciously used and simply recycled (111). Two other non-chlorinated solvents, cyclohexanone and $\gamma$-butyrolactone (GBL), were recently examined by Jiang and colleagues to extract PHA from microbial biomass. The biopolyester used in this study was produced by the bacterium Cupriavidus necator H16 by conversion of vegetable oil as the sole carbon source. Using cyclohexanone as solvent at $120^{\circ} \mathrm{C}, 95 \%$ of PHA was extracted from the cells within $3 \mathrm{~min}$; the product had a purity similar to that obtained using chloroform. GBL revealed considerably lower recovery yields at the same temperature. For both solvents, the molecular mass and dispersity of PHA were similar to chloroform-extracted products, while the contamination of the polymers by nitrogen residues was marginally higher when extracted using the two new solvents than in the reference case with chloroform. Especially cyclohexanone turned out as a proficient candidate for new, sustainable processes for PHA recovery (112). Technically more advanced approaches for solvent-based PHA extraction resort to special equipment, which allows extracting PHA under extreme process conditions with benign solvents; in this context, Koller et al. described an extraction apparatus, which was successfully used to extract PHA from microbial biomass under elevated temperature and pressure by using acetone as solvent, which does not dissolve crystalline PHA like poly(3-hydroxybutyrate) (PHB) or PHBHV under ambient conditions. Under conditions of about $120^{\circ} \mathrm{C}$ and 7 bar, it was possible to extract PHA at recovery yields and purity levels even exceeding those of parallel setups with chloroform. Cooling down the solution of PHA in acetone after extraction results in convenient precipitation of highly pure product, while residual biomass is retarded in an integrated filter system (113).

A completely different, entirely biological method of recovering PHA from bacterial biomass was developed by Ong and colleagues; these authors used larvae of the mealworm beetle Tenebrio molitor as PHA-recovery engine. These insects were fed with PHA-rich biomass of C. necator, whereby they digested the non-PHA part of biomass. The remaining white fecal pellets were simply washed with alkaline water. Purity of PHA obtained by this unique process amounted to $94 \%$; moreover, the product did not show any reduction of molecular mass (114). 
Major fields of application for PHA and follow-up products

Apart from the most prominent field of application of "bioplastics", namely replacing plastics as packaging materials, PHA enter to an increasing extent the therapeutic, surgical and tissue engineering realm. In this context, recent reviews summarize current strategies to produce PHA at purity levels required for in vivo use (115-120). Especially low endotoxin (lipopolysaccharides produced in the cell wall of Gram-negative microbes) levels are required for biopolymers used in vivo in order to prevent inflammatory reactions, which puts Gram-positive PHA production strains (no endotoxin producers) like Bacillus sp. or Streptomyces sp. in a new limelight (121). Such in vivo applications of PHA of varying compositions and their advanced follow-up products encompass carriers for triggered in vivo release of antibiotics or anti-cancer drugs, production of enhanced biodegradable sutures, surgical threads, implants or meshes, scaffolds for tissue engineering, or guidance conduits for nerve repair. To an increasing extend, especially PHA micro- and nanoparticles are used as carriers of active compounds, as demonstrated, e.g., by the retarded release of insulin from phospholipid-coated PHBHHx nano-spheres (122). In the field of cancer therapy, the cytostatic drug docetaxel can be delivered from nano-sized PHBHHx micelles to efficiently treat melanoma (123).

Particularly for the biomedical use, traditional processing techniques for production of PHA-based items, such as melt-spinning, melt extrusion, or solvent evaporation, get more and more outperformed by new emerging processing techniques such as additive manufacturing (3D-printing) to produce scaffolds for tissue engineering (124) or bone development (125), scaffold design by electrospinning (126) or computer-aided wet-spinning (127), or laser perforation (128) and plasma treatment (129) to enhance adhesion and attachment of stem cells and other cells to PHA surfaces. In vivo applicability of PHA can also be enhanced by post-synthetic functionalization of the biopolyesters; only recently, it was shown by Bhatia et al. that PHA functionalized with ascorbic acid provides a new biomaterial with decreased crystallinity, enhanced hydrophilicity, increased thermal degradation temperature, and superior biodegradability; these authors proposed this new product as powerful in vivo radical scavenger (130). In addition to the biomedical use of PHA in its polymeric form, it should be emphasized that the monomeric building blocks obtained by hydrolysis of microbial PHA reveal pharmaceutical activity, as demonstrated by the mitochondria protection mechanism exerted by 3-hydroxybutyrate (3HB), which makes this monomer active against the Alzheimer's disease (131).

Apart from the biomedical field, another important direction of development is the design of PHA-based composite materials to be used for smart food packaging (132). Recent reviews on this topic underline especially the importance of nanotechnology to improve the properties of PHA-based packaging materials (133-135). In general, the inherent shortcomings of some biodegradable polymers like PHA such as mod- est mechanical properties, thermo-oxidative stability, narrow processing windows, and insufficient electrical and thermal properties can be overcome by producing PHA-based composites reinforced with various nanofillers (136). For food packaging, high gas barrier properties are of special importance. In this context, Kovalcik et al. combined PHA with optimized amounts of lignin by thermoforming to design new composite materials for packaging. The impact of the lignin fraction on melting and crystallization behavior, mechanical and viscoelastic properties, thermo-oxidative stability, and gas permeability was studied. Lignin turned out to be highly compatible with the biopolyester, and acted as active additive by reinforcing the polymer. Gas permeability decreased by $77 \%$ for oxygen and by $91 \%$ for $\mathrm{CO}_{2}$, respectively, when combining PHA with $1 \mathrm{wt}$-\% lignin. Also thermo-oxidation stability was drastically increased for the materials containing lignin. The authors suggested the use of this new class of PHA-based materials for packaging especially of easily perishable goods like food (137).

Barrier properties of biopolymers can also be improved by developing multi-layer biocomposites, as demonstrated by Fabra et al., who designed multi-layer composites for potential food packaging applications; in this study, layers obtained by melt blending of thermoplastic starch and bacterial nanocellulose whiskers were combined with layers of hybrid electrospun PHA reinforced with bacterial nanocellulose. These composites exerted excellent adhesion between the layers, and superior barriers for oxygen and water, as desired for the purpose of food packaging (138). Apart from organic nanofillers, also inorganic materials can be used to improve PHA properties as packaging material (139). Only recently, Akin and Tihminlioglu investigated the impact of nano-clay particles on water permeability and mechanical properties of PHA homo- and copolyesters. It turned out that, provided an optimal distribution of the nanoparticles in the polymer matrix, water vapor permeability can be drastically reduced, while both tensile strength and strain at break can be significantly increased in PHA samples loaded with $3 \%$ nano-clay (140).

\section{Holistic life cycle considerations of the entire PHA production chain}

As mentioned before, the motivation to gradually switch towards polymers originated from renewable resources is their hypothetical benefit regarding their environmental impact when compared with their petrol-based challengers. This assumption is generally due to the belief that materials based on renewable resources hold an intrinsic environmental benefit over those based on fossil resources. However, this statement has to be validated as the case arises by assessing all the ecological impacts caused by the production of a given material along its entire life cycle, which spans the bridge from production of the raw material to the fate of the final product after its use. Only systematic and complete life cycle assessments (LCA) are appropriate tools to deliver solid, quantifiable and comprehensive data about the ecological footprint of products; this is the conditio sine qua non needed to reliably answer the question 


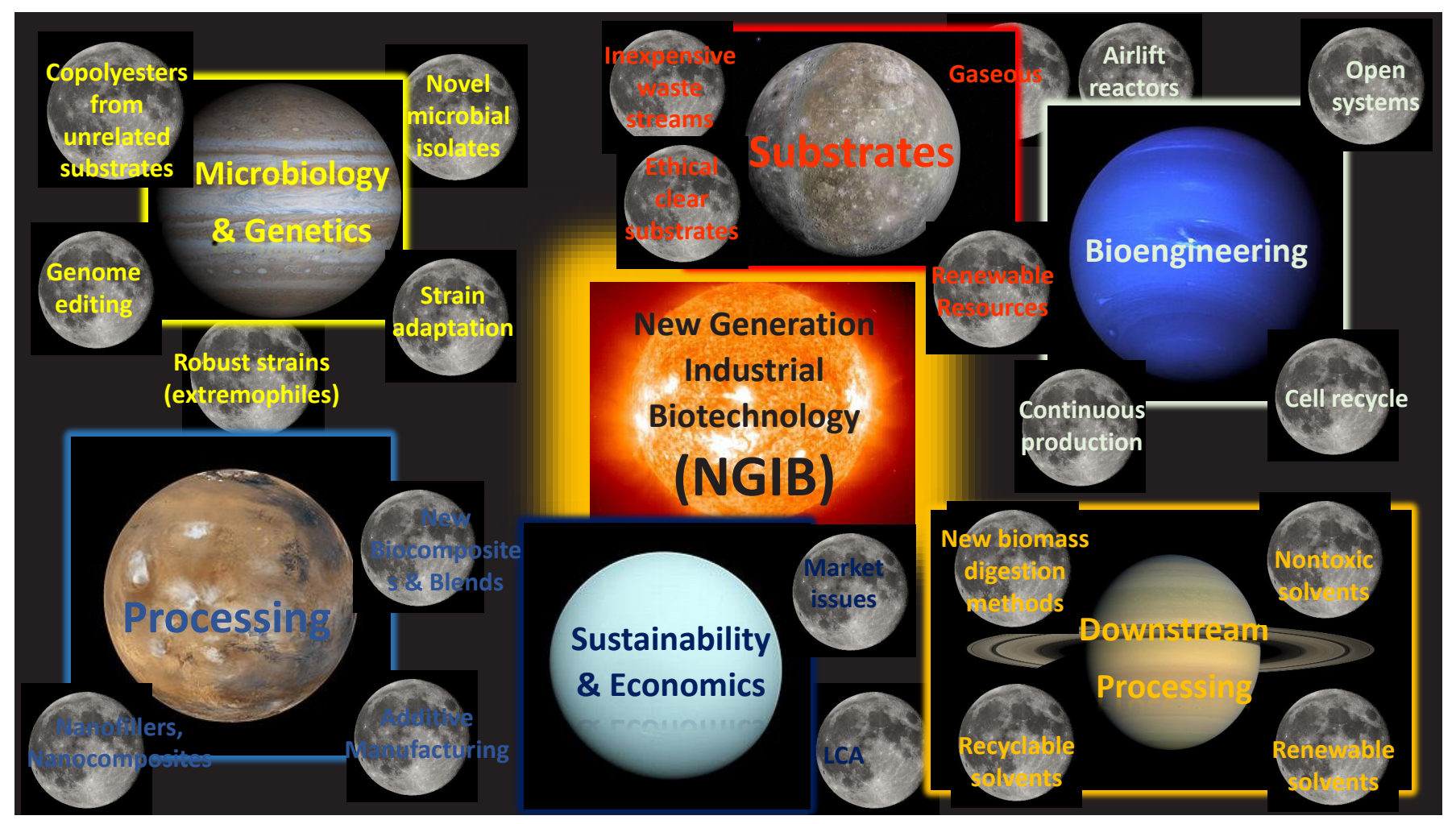

Figure 3. Visual illustration of PHA biopolyester manufacturing process.

if a given "bioplastic" like PHA and its follow-up products are that superior to outperform established petrol-based plastics in terms of their environmental performance.

As recently reviewed, the current discourse about environmental performance of PHA is exhaustively and controversially discussed in the present scientific literature (17). Based on these studies, it becomes clear that all of the above discussed stages of the PHA production chain need to be considered to identify the most important factors, which decide about the ecological performance of PHA and other biopolymers, and, most of all, to recognize the major fields for further process improvement that, without any doubt, are still present in the PHA production chain. However, comparing these studies makes it clear that PHA-based plastic products can indeed excel fossil competitors regarding their ecological performance, especially if their production is based on the use of (agro)industrial waste and by-products, the use of energy from clean sources, the switch to sustainable techniques for PHA recovery, an optimized bioengineering to run cultivation processes at maximum efficiency in terms of substrate-and energy demand, and the closing of the material cycles. Comprehensive LCA studies for PHA production based on (surplus) products from sugar industry (141), cheese making industry (45), animal processing industry (142144), or soybean oil manufacturing (145) clearly substantiate this paradigm. Most of all, these studies underline that, in order to safe transportation costs, efficient PHA production needs to be carried out in-house, hence, in close vicinity to the (agro) industrial production plant, where the substrates used for PHA production accrues as waste stream. Biorefinery concepts, such as those presented in the case of PHA production from animal processing waste or from lignocelluloses, are currently considered those solutions with highest potential for large-scale realization (146). These biorefinery concepts increasingly resort to the implementation of microbial cell factories engineered by the tools of synthetic biology, and especially to robust, often extremophilic production strains, which saves costs for precursor substrates, energy, and quality requirements set for the bioreactor.

\section{Conclusion}

By the "Next Generation Industrial Biotechnology" (NGIB) approach described in this review article, PHA and follow-up products can become key players in the emerging global bio-economy game, which is nowadays in the focus of decision makers and opinion leaders from politics and the industrial sector in many global regions (147). As a final summary, Fig. 3 provides a schematic sketch of the entire PHA production chain; in this illustration, the individual key stages of the process are illustrated as planets surrounding the holistic NGIB concept illustrated as central star. The moons circling around the planets illustrate the particular tasks assigned to the process stages, which have to be optimized and considered to develop an economically, ethically and environmentally sustainable PHA production process.

\section{References}

1. Haider TP, Völker C, Kramm J, Landfester K, Wurm FR. Plastics of the future? The impact of biodegradable polymers on the environment and on society. Angew Chem Int Edit 2019; 58(1): 50-62. 
2. Mathuriya AS, Yakhmi JV. Polyhydroxyalkanoates: Biodegradable Plastics and Their Applications. In: Martínez LM, Kharissova OV, Kharisov BI (Eds.): Handbook of Ecomaterials, 2017, pp. 1-29.

3. Geyer R, Jambeck JR, Law KL. Production, use, and fate of all plastics ever made. Sci Adv 2017; 3(7): e1700782.

4. Online resource 1: Last accessed June $25^{\text {th }}, 2018$ (in German) https://www.kleinezeitung.at/meinung/meinungktnhp/5438453/Kampf-gegen-Plastikmuell_Es-endet-nicht-beimTrinkhalm.

5. Online resource 2: Last accessed June $25^{\text {th }}, 2018$ (in German) https://www.kleinezeitung.at/service/newsticker/5439715/Thailand_Wal-verendete-an-ueber-80-Plastiksackerln-im-Magen.

6. Online resource 3: Last accessed June $25^{\text {th }}, 2018$ (in German) https://www.kleinezeitung.at/international/tiere/5533182/In-Indonesien-gefunden_Toter-Wal-mit-ueber-1100-Plastikteilen-im

7. Gajšt T, BizjakT, Palatinus A, Liubartseva S, Kržan A. Sea surface microplastics in Slovenian part of the Northern Adriatic. Mar Pollut Bull 2016; 113(1-2): 392-399.

8. Cesa FS, Turra A, Baruque-Ramos J. Synthetic fibers as microplastics in the marine environment: a review from textile perspective with a focus on domestic washings. Sci Total Environ 2017; 598: 1116-1129

9. Fonseca MMA, Gamarro EG, Toppe J, Bahri T, Barg U. The Impact of Microplastics on Food Safety: the Case of Fishery and Aquaculture Products. FAO Aquaculture Newsletter 2017; 57: 43-45.

10. Bouwmeester $\mathrm{H}$, Hollman PC, Peters RJ. Potential health impact of environmentally released micro-and nanoplastics in the human food production chain: experiences from nanotoxicology. Environ Sci Technol 2015; 49(15): 8932-8947.

11. Online resource 4: Last accessed October $24^{\text {th }}, 2018$ (in German) https://derstandard.at/2000089947285/Frage-und-Antwort-WieMikroplastik-in-den-Organismus-gelangt.

12. Jia P, Xia H, Tang K, Zhou Y. Plasticizers derived from biomass resources: a short review. Polymers 2018; 10(12): 1303.

13. Zhu Y, Romain C, Williams CK. Sustainable polymers from renewable resources. Nature 2016; 540(7633): 354

14. Koller M, Maršálek L, Miranda de Sousa Dias M, Braunegg G. Producing microbial polyhydroxyalkanoate (PHA) biopolyesters in a sustainable manner. New Biotechnol 2017; 37(A): 24-38.

15. Kourmentza C, Plácido J, Venetsaneas N, Burniol-Figols A, Varrone C, Gavala HN, Reis MAM. Recent advances and challenges towards sustainable polyhydroxyalkanoate (PHA) production. Bioengineering $2017 ; 4(2): 55$.

16. Akiyama M, Tsuge T, Doi Y. Environmental life cycle comparison of polyhydroxyalkanoates produced from renewable carbon resources by bacterial fermentation. Polym Degrad Stab 2003; 80(1): 183-194.

17. Narodoslawsky M, Shazad K, Kollmann R, Schnitzer H. LCA of PHA production-Identifying the ecological potential of bio-plastic. Chem Biochem Eng Q 2015; 29(2): 299-305.

18. Nielsen C, Rahman A, Rehman AU, Walsh MK, Miller CD. Food waste conversion to microbial polyhydroxyalkanoates. Microb Biotechnol 2017; 10(6): 1338-1352.

19. Kwan TH, Hu Y, Lin CSK. Techno-economic analysis of a food waste valorisation process for lactic acid, lactide and poly(lactic acid) production. J Clean Prod 2018; 181: 72-87.

20. Koller M, Braunegg G. Advanced approaches to produce polyhydroxyalkanoate (PHA) biopolyesters in a sustainable and economic fashion. The EuroBiotech Journal 2018; 2(2): 89-103.

21. Carvalho G, Oehmen A, Albuquerque MG, Reis MAM. The relationship between mixed microbial culture composition and PHA production performance from fermented molasses. New Biotechnol 2014; 31(4): 257-263.

22. Akaraonye E, Moreno C, Knowles JC, Keshavarz T, Roy I. Poly(3-hydroxybutyrate) production by Bacillus cereus SPV using sugarcane molasses as the main carbon source. Biotechnol J 2012; 7(2): 293 303.
23. Obruca S, Benesova P, Marsalek L, Marova I. Use of lignocellulosic materials for PHA production. Chem Biochem Eng Q 2015; 29(2): 135-144.

24. Lopes MSG, Gomez JGC, Taciro MK, Mendonça TT, Silva LF. Polyhydroxyalkanoate biosynthesis and simultaneous remotion of organic inhibitors from sugarcane bagasse hydrolysate by Burkholderia sp. J Ind Microbiol Biotechnol 2014; 41(9): 1353-1363.

25. Cesário MT, Raposo RS, de Almeida MCM, van Keulen F, Ferreira BS, da Fonseca MMR. Enhanced bioproduction of poly-3-hydroxybutyrate from wheat straw lignocellulosic hydrolysates. New Biotechnol 2014; 31(1): 104-113.

26. Ahn J, Jho EH, Kim M, Nam K. Increased 3 HV concentration in the bacterial production of 3-hydroxybutyrate (3HB) and 3-hydroxyvalerate (3HV) copolymer with acid-digested rice straw waste. J Polym Environ 2016; 24(2): 98-103.

27. Bowers T, Vaidya A, Smith DA, Lloyd-Jones G. Softwood hydrolysate as a carbon source for polyhydroxyalkanoate production. J Chem Technol Biotechnol 2014; 89(7): 1030-1037.

28. Kucera D, Benesova P, Ladicky P, Pekar M, Sedlacek P, Obruca S. Production of polyhydroxyalkanoates using hydrolyzates of spruce sawdust: Comparison of hydrolyzates detoxification by application of overliming, active carbon, and lignite. Bioengineering 2017: 4(2): 53.

29. Davis R, Kataria R, Cerrone F, Woods T, Kenny S, O'Donovan A, et al. Conversion of grass biomass into fermentable sugars and its utilization for medium chain length polyhydroxyalkanoate ( $m c /-P H A)$ production by Pseudomonas strains. Bioresource Technol 2013; 150: 202-209.

30. Kataria R, Woods T, Casey W, Cerrone F, Davis R, O'Connor K, et al. Surfactant-mediated hydrothermal pretreatment of Ryegrass followed by enzymatic saccharification for polyhydroxyalkanoate production. Ind Crop Prod 2018; 111: 625-632.

31. Zhang $Y$, Sun W, Wang H, Geng A. Polyhydroxybutyrate production from oil palm empty fruit bunch using Bacillus megaterium R11. Bioresource Technol 2013; 147: 307-314.

32. Sawant SS, Salunke BK, Kim BS. Degradation of corn stover by fungal cellulase cocktail for production of polyhydroxyalkanoates by moderate halophile Paracoccus sp. LL1. Bioresource Technol 2015, 194: 247-255.

33. Hokamura A, Yunoue Y, Goto S, Matsusaki H. Biosynthesis of polyhydroxyalkanoate from steamed soybean wastewater by a recombinant strain of Pseudomonas sp. 61-3. Bioengineering 2017; 4(3): 68.

34. Bhattacharya S, Dubey S, Singh P, Shrivastava A, Mishra S. Biodegradable polymeric substances produced by a marine bacterium from a surplus stream of the biodiesel industry. Bioengineering 2016; 3(4): 34.

35. Hermann-Krauss C, Koller M, Muhr A, Fasl H, Stelzer F, Braunegg G. Archaeal production of polyhydroxyalkanoate (PHA) co-and terpolyesters from biodiesel industry-derived by-products. Archaea 2013; 2013: article ID 129268.

36. Takahashi RYU, Castilho NAS, Silva MACD, Miotto MC, Lima AODS Prospecting for marine bacteria for polyhydroxyalkanoate production on low-cost substrates. Bioengineering 2017; 4(3): 60.

37. Koller M, Marsalek L. Principles of glycerol-based polyhydroxyalkanoate production. Applied Food Biotechnology 2015; 2(4): 3-10.

38. Koller M, Braunegg G. Biomediated production of structurally diverse poly(hydroxyalkanoates) from surplus streams of the animal processing industry. Polimery 2015; 60: 298-308.

39. Koller M, Shahzad K, Braunegg G. Waste Streams of the Animal-Processing Industry as Feedstocks to Produce Polyhydroxyalkanoate Biopolyesters. Applied Food Biotechnology 2018; 5(4): 193-203.

40. Neelamegam A, Al-Battashi H, Al-Bahry S, Nallusamy S. Biorefinery production of poly-3-hydroxybutyrate using waste office paper hydrolysate as feedstock for microbial fermentation. J Biotechnol 
2018; 265: 25-30.

41. Weissgram M, Gstöttner J, Lorantfy B, Tenhaken R, Herwig C, Weber HK. Generation of PHB from spent sulfite liquor using halophilic microorganisms. Microorganisms 2015; 3(2): 268-289.

42. Obruca S, Benesova P, Kucera D, Petrik S, Marova I. Biotechnological conversion of spent coffee grounds into polyhydroxyalkanoates and carotenoids. New Biotechnol 2015; 32(6): 569-574.

43. Kourmentza C, Costa J, Azevedo Z, Servin C, Grandfils C, De Freitas V, Reis MAM. Burkholderia thailandensis as a microbial cell factory for the bioconversion of used cooking oil to polyhydroxyalkanoates and rhamnolipids. Bioresource Technol 2018; 247: 829837.

44. Johnston B, Jiang G, Hill D, Adamus G, Kwiecień I, Zięba M, et al. The molecular level characterization of biodegradable polymers originated from polyethylene using non-oxygenated polyethylene wax as a carbon source for polyhydroxyalkanoate production. Bioengineering 2017; 4(3): 73.

45. Koller M, Sandholzer D, Salerno A, Braunegg G, Narodoslawsky M. Biopolymer from industrial residues: Life cycle assessment of poly (hydroxyalkanoates) from whey. Res Cons Recyc 2013; 73: 64-71.

46. Koller M, Puppi D, Chiellini F, Braunegg G. Comparing chemical and enzymatic Hydrolysis of whey lactose to generate feedstocks for haloarchaeal poly (3-hydroxybutyrate-co-3-hydroxyvalerate) biosynthesis. Int J Pharm Sci Res 2016; 3(1).

47. Kovalcik A, Kucera D, Matouskova P, Pernicova I, Obruca S, Kalina $M$, et al. Influence of removal of microbial inhibitors on PHA production from spent coffee grounds employing Halomonas halophila. J Environ Chem Eng 2018; 6(2): 3495-3501.

48. Keskin G, Kızıl G, Bechelany M, Pochat-Bohatier C, Öner M. Potential of polyhydroxyalkanoate (PHA) polymers family as substitutes of petroleum based polymers for packaging applications and solutions brought by their composites to form barrier materials. Pure Appl. Chem. 2017; 89 (12): 1841-1848

49. Bugnicourt E, Cinelli P, Lazzeri A, Alvarez VA. Polyhydroxyalkanoate (PHA): Review of synthesis, characteristics, processing and potential applications in packaging. eXPRESS Polym Lett 2014; 8(11): 791-808.

50. Mallegni N, Cinelli P, Balestri E, Lazzeri A, Seggiani M. New eco-composites based on polyhydroxyalkanoates $(\mathrm{PHA})$ for marine applications. J Adv Chem Eng 2016; 6(3): 70-70.

51. Lenz RW, Marchessault RH. Bacterial polyesters: biosynthesis, biodegradable plastics and biotechnology. Biomacromolecules 2005; 6: 1-8.

52. Braunegg G. Lefebvre G, Genser KF. Polyhydroxyalkanoates, biopolyesters from renewable resources: physiological and engineering aspects. J. Biotechnol 1998; 65: 127-161.

53. Obruca S, Sedlacek P, Koller M, Kucera D, Pernicova I. Involvement of polyhydroxyalkanoates in stress resistance of microbial cells: Biotechnological consequences and applications. Biotechnol Adv 2018; 36(3): 856-870.

54. Obruca S, Sedlacek P, Mravec F, Samek O, Marova I. Evaluation of 3-hydroxybutyrate as an enzyme-protective agent against heating and oxidative damage and its potential role in stress response of poly (3-hydroxybutyrate) accumulating cells. Appl Microbiol Biotechnol 2016; 100(3): 1365-1376.

55. Slaninova E, Sedlacek P, Mravec F, Mullerova L, Samek O, Koller $M$, et al., Light scattering on PHA granules protects bacterial cells against the harmful effects of UV radiation. Appl. Microbiol Biotechnol 2018; 102: 1923.

56. Obruca S, Sedlacek P, Krzyzanek V, Mravec F, Hrubanova K, Samek 0 , et al. Accumulation of poly (3-hydroxybutyrate) helps bacterial cells to survive freezing. PloS one 2016; 11(6): e0157778.

57. Sedlacek P, Slaninova E, Koller M, Nebesarova J, Marova I, Krzyzanek V, Obruca S. PHA granules help bacterial cells to preserve cell integrity when exposed to sudden osmotic imbalances. New Biotechnol 2019; 49(25): 129-136.

58. Obruca S, Marova I, Stankova M, Mravcova L, Svoboda Z. Effect of ethanol and hydrogen peroxide on poly (3-hydroxybutyrate) biosynthetic pathway in Cupriavidus necator H16. World J Microbiol Biotechnol 2010; 26(7): 1261-1267.

59. Al Rowaihi IS, Paillier A, Rasul S, Karan R, Grötzinger SW, Takanabe $\mathrm{K}$, Eppinger J. Poly(3-hydroxybutyrate) production in an integrated electromicrobial setup: Investigation under stress-inducing conditions. PloS one 2018; 13(4), e0196079.

60. González-García Y, Nungaray J, Córdova J, González-Reynoso O Koller M, Atlić A, Braunegg G. Biosynthesis and characterization of polyhydroxyalkanoates in the polysaccharide-degrading marine bacterium Saccharophagus degradans ATCC 43961. J Ind Microbiol Biotechnol 2008; 35(6): 629-633.

61. Montenegro EMDS, Delabary GS, Silva MACD, Andreote FD, Lima AODS. Molecular diagnostic for prospecting polyhydroxyalkanoate-producing bacteria. Bioengineering 2017; 4(2): 52.

62. Salgaonkar BB, Bragança JM. Utilization of sugarcane bagasse by Halogeometricum borinquense strain E3 for biosynthesis of poly(3-hydroxybutyrate-co-3-hydroxyvalerate). Bioengineering 2017; 4(2): 50.

63. Yin J, Chen JC, Wu Q, Chen GQ. Halophiles, coming stars for industrial biotechnology. Biotechnology Adv 2015; 33(7): 1433-1442.

64. Chen GQ, Jiang XR. Next generation industrial biotechnology based on extremophilic bacteria. Curr Opin Biotech 2018; 50: 94100.

65. Chen GQ, Jiang XR. Engineering microorganisms for improving polyhydroxyalkanoate biosynthesis. Curr Opin Biotech 2018; 53: 20-25.

66. Povolo S, Toffano P, Basaglia M, Casella, S. Polyhydroxyalkanoates production by engineered Cupriavidus necator from waste material containing lactose. Bioresource Technol 2010; 101(20): 79027907.

67. Ouyang P, Wang H, Hajnal I, Wu Q, Guo Y, Chen GQ. Increasing oxygen availability for improving poly(3-hydroxybutyrate) production by Halomonas. Metab Eng 2018; 45: 20-31.

68. Ling C, Qiao GQ, Shuai BW, Olavarria K, Yin J, Xiang RJ, et al. Engineering $\mathrm{NADH} / \mathrm{NAD}^{+}$ratio in Halomonas bluephagenesis for enhanced production of polyhydroxyalkanoates (PHA). Metab Eng 2018; 49: 275-286.

69. Qin Q, Ling C, Zhao Y, Yang T, Yin J, Guo Y, Chen GQ. CRISPR/Cas9 editing genome of extremophile Halomonas spp. Metab Eng 2018; 47: 219-229.

70. Liu Q, Luo G, Zhou XR, Chen GQ. Biosynthesis of poly(3-hydroxydecanoate) and 3-hydroxydodecanoate dominating polyhydroxyalkanoates by $\beta$-oxidation pathway inhibited Pseudomonas putida. Metab Eng 2011; 13(1): 11-17.

71. Shen R, Cai L, Meng D, Wu L, Guo K, Dong G, et al. Benzene containing polyhydroxyalkanoates homo-and copolymers synthesized by genome edited Pseudomonas entomophila. Science China Life Sciences 2014; 57(1), 4-10.

72. Wei X, Liu F, Jian J, Wang R, Chen GQ. Production of Poly (3-hydroxybutyrate-co-3-hydroxyhexanoate) by Recombinant Pseudomonas stutzeri 1317 from Unrelated Carbon Sources. Chinese J Chem Eng 2013; 21(9): 1057-1061.

73. Zhou XY, Yuan XX, Shi ZY, Meng DC, Jiang WJ, Wu LP., et al. Hyperproduction of poly (4-hydroxybutyrate) from glucose by recombinant Escherichia coli. Microb Cell Fact 2012; 11(1): 54.

74. Gamero JER, Favaro L, Pizzocchero V, Lomolino G, Basaglia M, Casella S. Nuclease expression in efficient polyhydroxyalkanoates-producing bacteria could yield cost reduction during downstream processing. Bioresource Technol 2018; 261: 176-181.

75. Favaro L, Basaglia M, Casella S. Improving polyhydroxyalkanoate production from inexpensive carbon sources by genetic approaches: a review. Biofuel Bioprod Bior 2018; online ahead of press; doi: 10.1002/bbb

76. Koller M, Bona R, Chiellini E, Fernandes EG, Horvat P, Kutscher C., et al. Polyhydroxyalkanoate production from whey by Pseudomonas hydrogenovora. Biores Technol 2008; 99(11): 4854-4863. 
77. Blunt W, Levin D, Cicek N. Bioreactor Operating Strategies for Improved Polyhydroxyalkanoate (PHA) Productivity. Polymers 2018; 10(11): 1197

78. Koller M. A review on established and emerging fermentation schemes for microbial production of Polyhydroxyalkanoate (PHA) biopolyesters. Fermentation 2018: 4(2), 30.

79. Braunegg G, Lefebvre G, Renner G, Zeiser A, Haage G, Loidl-Lanthaler K. Kinetics as a tool for polyhydroxyalkanoate production optimization. Can J Microbiol 1995; 41(13): 239-248.

80. Sindhu R, Silviya N, Binod P, Pandey A. Pentose-rich hydrolysate from acid pretreated rice straw as a carbon source for the production of poly-3-hydroxybutyrate. Biochem Eng J 2013; 78: 67-72.

81. Gahlawat G, Srivastava AK. Enhancing the production of polyhydroxyalkanoate biopolymer by Azohydromonas australica using a simple empty and fill bioreactor cultivation strategy. Chem Biochem Eng Q 2018; 31(4): 479-485.

82. Miranda de Sousa Dias M, Koller M, Puppi D, Morelli A, Chiellini F Braunegg G. Fed-Batch synthesis of poly(3-hydroxybutyrate) and poly(3-hydroxybutyrate-co-4-hydroxybutyrate) from sucrose and 4-hydroxybutyrate precursors by Burkholderia sacchari strain DSM 17165. Bioengineering 2017; 4: 36

83. Ibrahim M.H, Steinbüchel A. High-cell-density cyclic fed-batch fermentation of a poly(3-hydroxybutyrate)-accumulating thermophile, Chelatococcus sp. strain MW10. Appl Environ Microbio 2010; 76: 7890-7895.

84. Haas C, El-Najjar T, Virgolini N, Smerilli M, Neureiter M. High cell-density production of poly(3-hydroxybutyrate) in a membrane bioreactor. New Biotechnol 2017; 37: 117-122.

85. Koller M, Muhr A. Continuous production mode as a viable process-engineering tool for efficient poly(hydroxyalkanoate)(PHA) bio-production. Chem Biochem Eng Q 2014; 28(1): 65-77.

86. Koller M, Braunegg G. Potential and prospects of continuous polyhydroxyalkanoate (PHA) production. Bioengineering 2015; 2(2): 94-121.

87. Atlić A, Koller M, Scherzer D, Kutschera C, Grillo-Fernandes E, Horvat $\mathrm{P}$, et al. Continuous production of poly $([R]-3$-hydroxybutyrate $)$ by Cupriavidus necator in a multistage bioreactor cascade. Appl Microbiol Biotechnol 2011; 91(2): 295-304.

88. Horvat P, Špoljarić IV, Lopar M, Atlić A, Koller M, Braunegg G. Mathematical modelling and process optimization of a continuous 5-stage bioreactor cascade for production of poly[-(R)-3-hydroxybutyrate] by Cupriavidus necator. Bioproc Biosyst Eng 2013; 36(9): 1235-1250.

89. Lopar M, Špoljarić IV, Atlić A, Koller M, Braunegg G, Horvat P. Fivestep continuous production of PHB analyzed by elementary flux, modes, yield space analysis and high structured metabolic model. Biochem Eng J 2013; 79: 57-70.

90. Vadlja D, Koller M, Novak M, Braunegg G, Horvat P. Footprint area analysis of binary imaged Cupriavidus necator cells to study PHB production at balanced, transient, and limited growth conditions in a cascade process. Appl Microbiol Biotechnol 2016; 100(23): 10065-10080.

91. Koller M, Vadlja D, Braunegg G, Atlić A, Horvat P. Formal-and high-structured kinetic process modelling and footprint area analysis of binary imaged cells: Tools to understand and optimize multistage-continuous PHA biosynthesis. The EuroBiotech Journal 2017; 1(3): 203-211.

92. Koller M; Maršálek L: Cyanobacterial polyhydroxyalkanoate production: status quo and quo vadis? Curr Biotechnol 2015; 4(4): 464480.

93. Drosg B, Fritz I, Gattermayr F, Silvestrini L. Photo-autotrophic production of poly(hydroxyalkanoates) in cyanobacteria. Chem Biochem Engineering Q 2015; 29(2): 145-156.

94. Costa JAV, Moreira JB, Lucas BF, Braga VDS, Cassuriaga APA, Morais MGD. Recent Advances and Future Perspectives of PHB Production by Cyanobacteria. Industrial Biotechnol 2018; 14(5): 249-256.

95. Koller M Khosravi-Darani K, Braunegg G. Advanced Photobioreac- tor Systems for the Efficient Cultivation of Cyanobacteria. In: Yiu Fai Tsang (Ed.): PhotobioreactorsAdnacements, Applications and Research. New York. Nova Science Publishers, 2017, pp. 35-90.

96. Troschl C, Meixner K, Drosg B. Cyanobacterial PHA productionReview of recent advances and a summary of three years' working experience running a pilot plant. Bioengineering 2017: 4(2): 26.

97. Tanaka K, Miyawaki K, Yamaguchi A, Khosravi-Darani K, Matsusaki $\mathrm{H}$. Cell growth and $\mathrm{P}(3 \mathrm{HB})$ accumulation from $\mathrm{CO} 2$ of a carbon monoxide-tolerant hydrogen-oxidizing bacterium, Ideonella sp. O-1, Appl Microbiol Biotechnol 2011; 92(6): 1161-1169.

98. Khosravi-Darani K, Vasheghani-Farahani E, Tanaka K. Hydrogen-oxidizing bacteria as poly(hydroxybutyrate) producers. Iran J Biotechnol 2006; 4: 193-196.

99. Khosravi-Darani K, Mokhtari ZB, Amai T, Tanaka K. Microbial production of poly(hydroxybutyrate) from $\mathrm{C} 1$ carbon sources. Appl Microb Biotechnol 2013; 97(12): 56-57.

100. Mokhtari-Hosseini ZB, Vasheghani-Farahani E, Heidarzadeh-Vazifekhoran A, Shojaosadati SA, Karimzadeh R, Khosravi-Darani K. Statistical media optimization for growth and PHB production from methanol by a methylotrophic bacterium. Bioresour Technol 2009; 100: 2436-2443.

101. Mokhtari-Hosseini ZB, Vasheghani-Farahani E, Shojaosadati SA, Karimzadeh R, Heidarzadeh-Vazifekhoran A. Effect of feed composition on PHB production from methanol by HCDC Methylobacterium extorquens (DSMZ 1340). J Chem Technol Biotechnol 2009; 84: 1136-1139.

102. Strong $P$, Laycock B, Mahamud S, Jensen P, Lant P, Tyson G, Pratt S. The opportunity for high-performance biomaterials from methane. Microorganisms 2016; 4(1): 11.

103. Revelles O, Tarazona N, García JL, Prieto MA. Carbon roadmap from syngas to polyhydroxyalkanoates in Rhodospirillum rubrum. Environ Microbiol 2016; 18(2): 708-720.

104. Heinrich D, Raberg M, Fricke P, Kenny ST, Morales-Gamez L, Babu $\mathrm{RP}$, et al. Syngas-derived medium-chain-length PHA synthesis in engineered Rhodospirillum rubrum. Appl Environ Microbiol 2016; 82(20); 6132-6149 (AEM-01744).

105. Khosravi-Darani K, Yazdian F, Rashedi H, Mofradnia SR, Moradi M, Madadian-Bozorg N, Koller M. Simulation of bioreactors for poly(3-hydroxybutyrate) production from natural gas. Iran J Chem Chem Eng 2019; 39(1) (online ahead of print).

106. Karmann S, Follonier S, Egger D, Hebel D, Panke S, Zinn M. Tailormade PAT platform for safe syngas fermentations in batch, fedbatch and chemostat mode with Rhodospirillum rubrum. Microb Biotechnol 2017; 10(6): 1365-1375.

107. Kosseva MR, Rusbandi E. Trends in the biomanufacture of polyhydroxyalkanoates with focus on downstream processing. Int J Biol Macromolecul 2018; 107(A): 762-778

108. Koller M, Niebelschütz H, Braunegg G. Strategies for recovery and purification of poly[(R)-3-hydroxyalkanoates] (PHA) biopolyesters from surrounding biomass. Eng Life Sci 2013; 13(6): 549-562.

109. Madkour MH, Heinrich D, Alghamdi MA, Shabbaj II, Steinbüchel A. PHA recovery from biomass. Biomacromolecules 2013; 14(9): 2963-2972

110. Marudkla J, Patjawit A, Chuensangjun C, Sirisansaneeyakul S. Optimization of poly (3-hydroxybutyrate) extraction from Cupriavidus necator DSM 545 using sodium dodecyl sulfate and sodium hypochlorite. Agric Natural Res 2018; 52(3): 266-273

111. Samorì C, Basaglia M, Casella S, Favaro L, Galletti P, Giorgini L, et al. Dimethyl carbonate and switchable anionic surfactants: two effective tools for the extraction of polyhydroxyalkanoates from microbial biomass. Green Chem 2015; 17(2): 1047-1056.

112. Jiang $G$, Johnston B, Townrow D, Radecka I, Koller M, Chaber $\mathrm{P}_{\text {, }}$ et al. Biomass Extraction Using Non-Chlorinated Solvents for Biocompatibility Improvement of Polyhydroxyalkanoates. Polymers 2018; 10(7): 731.

113. Koller M, Bona R, Chiellini E, Braunegg G. Extraction of shortchain-length poly-[(R)-hydroxyalkanoates] (scl-PHA) by the "an- 
ti-solvent" acetone under elevated temperature and pressure. Biotechnol Lett 2013; 35(7): 1023-1028.

114. Ong SY, Zainab-L I, Pyary S, Sudesh K. A novel biological recovery approach for PHA employing selective digestion of bacterial biomass in animals. Appl Microbiol Biotechnol 2018; 122(5): 21172127.

115. Chen GQ, Wang Y. Medical applications of biopolyesters polyhydroxyalkanoates. Chinese J Polym Sci 2013; 31(5): 719-736.

116. Koller M. Biodegradable and biocompatible polyhydroxy-alkanoates (PHA): Auspicious microbial macromolecules for pharmaceutical and therapeutic applications. Molecules 2018; 23(2): 362.

117. Peptu C, Kowalczuk M. Biomass-derived polyhydroxyalkanoates: Biomedical applications. In: Popa V, Volf I (Eds.), Biomass as renewable raw material to obtain bioproducts of high-tech value. Elsevier, 2018; pp. 271-313.

118. Butt Fl, Muhammad N, Hamid A, Moniruzzaman M, Sharif F. Recent progress in the utilization of biosynthesized polyhydroxyalkanoates for biomedical applications-Review. Int J Biol Macromol 2018; 120(A): 1294-1305.

119. Zinn M, Witholt B, Egli T. Occurrence, synthesis and medical application of bacterial polyhydroxyalkanoate. Adv Drug Deliver Rev 2001; 53(1): 5-21.

120. Luef KP, Stelzer F, Wiesbrock F. Poly(hydroxyalkanoate)s in medical applications. Chem Biochem Eng Q 2015; 29(2): 287-297.

121. Valappil SP, Boccaccini AR, Bucke C, Roy I. Polyhydroxyalkanoates in Gram-positive bacteria: insights from the genera Bacillus and Streptomyces. Antonie van Leeuwenhoek 2007; 91(1): 1-17.

122. Peng $Q$, Zhang ZR, Gong $T$, Chen $G Q$, Sun X. A rapid-acting, long-acting insulin formulation based on a phospholipid complex loaded PHBHHx nanoparticles. Biomaterials 2012; 33(5): 15831588.

123. Luo Z, Jiang L, Ding C, Hu B, Loh XJ, Li Z, Wu YL. Surfactant free delivery of docetaxel by poly [(R)-3-hydroxybutyrate-( $R$ )-3-hydroxyhexanoate]-based polymeric micelles for effective melanoma treatments. Adv Healthc Mater 2018; 1801221 (online ahead of print; doi: 10.1002/adhm.201801221).

124. Puppi D, Morelli A, Chiellini F. Additive manufacturing of poly(3-hydroxybutyrate-co-3-hydroxyhexanoate)/poly(E-caprolactone) blend scaffolds for tissue engineering. Bioengineering 2017; 4(2), 49.

125. Mota C, Wang SY, Puppi D, Gazzarri M, Migone C, Chiellini F, et al. (2017). Additive manufacturing of poly [(R)-3-hydroxybutyrateco-(R)-3-hydroxyhexanoate] scaffolds for engineered bone development. J Tissue Eng Regen M 2017; 11(1): 175-186.

126. Sanhueza C, Acevedo F, Rocha S, Villegas P, Seeger M, Navia R. Polyhydroxyalkanoates as biomaterial for electrospun scaffolds. Int J Biol Macromol 2018; online ahead of print; doi: 10.1016/j. ijbiomac.2018.11.068

127. Puppi D, Pirosa A, Morelli A, Chiellini F. Design, fabrication and characterization of tailored poly[( $R)$-3-hydroxybutyrate-co- $(R)-3$-hydroxyexanoate] scaffolds by computer-aided wet-spinning. Rapid Prototyping J 2018; 24(1): 1-8.

128. Ellis G, Cano P, Jadraque M, Martín M, López L, Núñez T, et al. Laser microperforated biodegradable microbial polyhydroxyalkanoate substrates for tissue repair strategies: an infrared microspectroscopy study. Anal Bioanal Chem 2011; 399(7): 2379-2388.

129. Chang CK, Wang HMD, Lan JCW. Investigation and characterization of plasma-treated poly(3-hydroxybutyrate) and poly(3-hydroxybutyrate-co-3-hydroxyvalerate) Biopolymers for an in vitro cellular study of mouse adipose-derived stem cells. Polymers 2018; 10(4): 355

130. Bhatia SK, Wadhwa P, Hong JW, Hong YG, Jeon JM, Lee ES, Yang $\mathrm{YH}$. Lipase mediated functionalization of poly (3-hydroxybutyrate-co-3-hydroxyvalerate) with ascorbic acid into an antioxidant active biomaterial. Int J Biol Macromol 2019; 123(15): 117-123.
131. Zhang J, Cao Q, Li S, Lu X, Zhao Y, Guan JS, et al. 3-Hydroxybutyrate methyl ester as a potential drug against Alzheimer's disease via mitochondria protection mechanism. Biomaterials 2013; 34(30), 7552-7562.

132. Rydz J, Musioł M, Zawidlak-Węgrzyńska B, Sikorska W. Present and Future of Biodegradable Polymers for Food Packaging Applications. In: (Grumezescu AM, Holban AM, Eds.): Biopolymers for Food Design - A volume in Handbook of Food Bioengineering 2018: pp. 431-467.

133. Plackett D, Siró I. Polyhydroxyalkanoates (PHAs) for food packaging. In: Lagarón JM (Ed.): Multifunctional and nanoreinforced polymers for food packaging. Elsevier, 2011; pp. 498-526.

134. Koller M. Poly(hydroxyalkanoates) for food packaging: Application and attempts towards implementation. App Food Biotechnol 2014; 1(1): 3-15.

135. Khosravi-Darani K, Bucci DZ. Application of poly(hydroxyalkanoate) in food packaging: Improvements by nanotechnology. Chem Biochem Engineering Q 2015; 29(2): 275-285.

136. Sun J, Shen J, Chen S, Cooper M, Fu H, Wu D, Yang Z. Nanofiller reinforced biodegradable PLA/PHA composites: Current status and future trends. Polymers 2018; 10(5): 505.

137. Kovalcik A, Machovsky M, Kozakova Z, Koller M. Designing packaging materials with viscoelastic and gas barrier properties by optimized processing of poly (3-hydroxybutyrate-co-3-hydroxyvalerate) with lignin. React Funct Polym 2015; 94: 25-34.

138. Fabra MJ, López-Rubio A, Ambrosio-Martín J, Lagaron JM. Improving the barrier properties of thermoplastic corn starch-based films containing bacterial cellulose nanowhiskers by means of PHA electrospun coatings of interest in food packaging. Food Hydrocolloid 2016; 61: 261-268.

139. Bordes P, Pollet E, Bourbigot S, Averous L. Structure and Properties of PHA/Clay Nano-Biocomposites Prepared by Melt Intercalation. Macromol Chem Physic 2008; 209(14): 1473-1484.

140. Akin O, Tihminlioglu F. Effects of organo-modified clay addition and temperature on the water vapor barrier properties of polyhydroxy butyrate homo and copolymer nanocomposite films for packaging applications. J Polym Environ 2018; 26(3): 1121-1132.

141. Harding KG, Dennis JS, Von Blottnitz H, Harrison STL. Environmental analysis of plastic production processes: comparing petroleum-based polypropylene and polyethylene with biologically-based poly- $\beta$-hydroxybutyric acid using life cycle analysis. J Biotechnol 2007; 130(1): 57-66.

142. Titz M, Kettl KH, Shahzad K, Koller M, Schnitzer H, Narodoslawsky $M$. Process optimization for efficient biomediated PHA production from animal-based waste streams. Clean Technol Environ Pol. 2012; 14: 495-503.

143. Shahzad K, Kettl KH, Titz M, Koller M, Schnitzer H, Narodoslawsky M. Comparison of ecological footprint for biobased PHA production from animal residues utilizing different energy resources. Clean Technol Environ Pol. 2013; 15: 525-536.

144. Shahzad K, Narodoslawsky M, Sagir M, Ali N, Ali S, Rashid Ml, et al. Techno-economic feasibility of waste biorefinery: Using slaughtering waste streams as starting material for biopolyester production. Waste Manage 2017; 67: 73-85.

145. Kookos IK, Koutinas A, Vlysidis A. Life cycle assessment of bioprocessing schemes for poly (3-hydroxybutyrate) production using soybean oil and sucrose as carbon sources. Resour Conserv Recy 2019; 141:317-328.

146. Jiang G, Hill DJ, Kowalczuk M, Johnston B, Adamus G, Irorere V, Radecka I. Carbon sources for polyhydroxyalkanoates and an integrated biorefinery. Int J Mol Sci 2016; 17(7): 1157.

147. Dietrich K, Dumont MJ, Del Rio LF, Orsat V. Producing PHAs in the bioeconomy-Towards a sustainable bioplastic. Sust Prod Consum 2017; 9: 58-70. 